\title{
E-DIAGNOSIS: KNOWLEDGE MANAGEMENT AND ORGANIZATIONAL CHANGE IN VIRTUAL TIMES
}

\author{
Paulo S. Grave \\ Universidade Estadual de Maringá \\ pgrave@uol.com.br \\ Fernando A. Gimenez \\ Universidade Estadual de Maringá \\ fapgimenez@uol.com.br \\ Ariston A. Mendes \\ Universidade Estadual de Maringá \\ ariston@wnet.com.br \\ João M. Crubellate \\ Universidade Estadual de Maringá \\ jmcrubellate@uem.br \\ $B R A Z I L$
}

\begin{abstract}
This paper discusses E-diagnosis, i.e., organizational diagnosis in electronic terms. E-diagnosis is taken as an instrument of meaningful knowledge construction for managers, based on a set of data and organizational information obtained in almost real time. Actually, based on a criticism of conventional modes of organizational status assessment, the intention is to configure a virtual mode of approaching the problem faced by those who manage - how to assure organizational long term survival. Attention is not focused too much in Information Technology - IT, however current IT advances are considered and taken as a support to organizational virtualization. Thus, the possibility of assuring appropriate information for managerial decision processes is delineated considering four dimensions - format, content, time, and cultural space.
\end{abstract}

\section{INTRODUCTION}

Debates on learning organizations (Senge et al., 1999) and organizational knowledge (Davenport \& Prusak, 1998), supported by developments in Information Technology (IT) and organizational networks (Lipnack \& Stamps, 1994), and more recently, influenced by the strong tendency of organizational virtualization (Cadoz, 1997), seem to implicate, in practical terms, in the possibility of knowledge electronization in a business environment. The first objective manifestations of such a theoretical connection can already be verified through the proliferation of the two most spread current electronic formats in the specialized and non-specialized literature, that is, EBusiness and E-Commerce. Such business forms point to a new status in knowledge and organizations management (Champy \& Nohria, 1997), which in turn, bring

The original version of this chapter was revised: The copyright line was incorrect. This has been corrected. The Erratum to this chapter is available at DOI: 10.1007/978-0-387-35399-9_52 
consequences that range from strategic movements (McGee \& Prusak, 1994) to tactical-operational ones (Poirier \& Reiter, 1997).

In this same vein of implications for current businesses, and in spite of deserving criticism, it is practically undeniable that operational tools as software, database and systems have been demanded more intensively to codify and to store "knowledge" on the organizational situation, that in our point of view, help the decision-maker appropriating, with larger speed, the reality of his/her interest, that is, of that reality where his/er action has significant effect. Saying in another way, the intensive application of those tools in organizations has made possible codifying, storage and distribution of information for the decision points, allowing those who accesses them, to build new and significant knowledge regarding the situation they want to manage.

Thus, in times of undeniable (and inevitable) organizational and administrative virtualization, the success of a virtual corporation (or not) seems to be linked to the capacity of the administrator "to collect and to integrate a great flow of information in all organizational components and to act in an intelligent way in function of those information" (Davidow \& Malone, 1993:55). This seems to indicate that this environment type no longer legitimates diagnosis in the terms that has been prevailing in management manuals. In fact, it seems to be necessary that organizational diagnosis loses punctual, static character, that up to now has been prevailing in the administrative literature, and take, in fact, a dynamic character. Times are ripe for another diagnosis practice.

It is in face of such context that we are tempted to insert the concept of EDiagnosis, i. e., electronic or virtual organizational diagnosis, whose purpose is to serve as a tool to increase the decision-making capacity of those who manage, that in this specific case is attributed to be the manager ${ }^{1}$. E-Diagnosis brings for management a new possibility so that, in almost real time, the manager can build significant knowledge on certain organizational situation and, thus, to decide in an appropriate way.

\section{ORGANIZATIONAL DIAGNOSIS AND KNOWLEDGE CONSTRUCTION BY THE MANAGER}

Based on a possible interpretation of Hessen (1980) and Chauí (1999), we define knowledge as the appropriation of the object by the subject. Knowledge is something idiosyncratic. In other words, it is owned by each individual. To each individual a specific appropriation of certain object, a construction that is his/er own. Or as Hessen affirmed, "in knowledge conscience and object, subject and object are face to face. Knowledge comes as a relationship among these two elements, that stay eternally apart one from the other. The subject and object dualism belongs to the essence of knowledge" (1980:26).

Thus, we identified a continuum, in form of a possible spiral, representative of such a process that oscillates from ignorance to the subject's wisdom regarding the object of knowledge. Along this continuum, in nominative terms, we will find evolutionary stages of appropriation of the object by the subject, identified through three specifying concepts: data, information, and knowledge in itself, in the stage 0 (ignorance level) to $\mathrm{n}$ (level of wisdom). “... the subject's function consists of apprehending the object, the one of the object in being apprehended by the subject" 
(Hessen, 1980:26). Put this way, it would implicate in permanent loops: of organizational data to knowledge in itself of the issue on the agenda. This would happen when the human individual could explain for him/herself or for others, the object of knowledge. However, considering the subject-object dualism, reaching, in fact, the stage of wisdom would be impossible for the human being.

In this sense, organizational diagnosis is definable as a tool to build certain knowledge on the organizational reality and to guide decision-makers in understanding it, foreseeing behavior of its essential elements and intervening in the relationships that grow in the ambit of the business, looking for its permanent adjustment (Grave \& Seixas, 1999). In summary, E-diagnosis is an instrument of creation of the knowledge of the organizational situation for decision-makers, particularly for managers.

\section{THE ISSUE OF THE SITUATION (OR STATE) OF THE ORGANIZATION: A REAL PROBLEM}

Concerning organizations, there is an issue that cannot be avoided: the problematic state of the organization is a permanent situation. Based on a dynamic definition of the concept of problem (Kepner \& Tregoe, 1980) or characterizing it as a permanent state that all and any organization can be found, we have it as the difference among two performance states: one that the organization is in -state A - and one that it should be in - state B -that assures its long term survival, in terms of time and cultural space ${ }^{2}$. As a consequence, three possible situations can happen: (1) the state that the organization is in - state $\mathrm{A}$ - is unfavorable, implicating in having to alter it - state B; (2) the state that it is in - state A - is what should be -state B, implicating in administrative decisions to maintain it; and (3) the state that it is in - state A - is favorable, but, could be inadequate in view of the environment, implicating in adjusting it to acceptable or compatible levels - state B.

Conformed like this, a manager has a permanent need: building an organizational knowledge that keeps him/her understanding the state of the referred conditions. It is in this context that we attribute basic importance to the knowledge that grows in the ambit of the organizations for its decision-makers. The concept of organizational diagnosis, then, results as an instrument to treat data, information and knowledge in itself regarding the reality of interest, looking for a significant knowledge on the organizational problem affected to who administers - for instance, the long term survival of the organization.

Thus, considering the inherent dynamics of the variables time and cultural space, an aspect is raised immediately: speed in the appropriation of the organizational problem. In this case, E-diagnosis would act as an instrument that would accelerate the perception of the data, the apprehension of the information and the appropriation of the organizational problem (Grave \& Seixas, 1999). Facing this problem, we thought about the issue on discussion, with the intention of construing an instrument that reduces the empty time that has been observed in the administrative decisionmaking process and in the manual way of examining the organization. Therefore, the quicker the understanding of the organizational situation, the larger the probability that there is time for administrative decisions of adjustment.

E-Diagnosis appears, in fact, representing, thus, a powerful group of intervening means - hardwares, softwares, databases etc - in organizational relationships or as a 
decision aid support (DAS), automating great part of the decision-making process in the organization. As a matter of fact, it becomes indispensable in view of specialized analysts' comments such as Davidow \& Malone (1993:47): “... the incremental differences in companies capacity to acquire, to distribute, to store, to analyze and to invoke actions based on information will determine who wins and who loses the battle for the customers." This exam mode seems to us an objective possibility of examining the organization, electronically and virtually, accelerating and, even, advancing the perception/apprehension of data and information to build a significant knowledge.

It is evident that the idea of configuring important groups of information about the situation, allowing the decision-maker to construct an organizational knowledge that matters, is an unequivocal fact. However, in spite of the present technological stage, that facilitates a physical structuring more and more potent, we still are in need of a convenient logical structuring, that allows us to attend the contemporary administrative demands, or face the existent competitive environment, with nothing indicating that it will not last long. "The managers face an impressive challenge in this competitive and ever-changing environment - and it is not a passing phenomenon" (Rummler \& Brache, 1992:xvi). Thus, we will consider issues that allow us to delineate the logical structuring of the electronic diagnosis in organizations.

\section{DEVELOPMENT OF THE SCHEME: LOOKING FOR AN APPROPRIATE METHOD}

The issue is surrounded by natural inquiries, when developing an information system, that allows us to construct knowledge for an effective decision: (1) which data should be obtained - amount, quality and cost - representing the initial content and the entrance or reception of the system?; (2) how should the data be located for the manipulation that is necessary, representing the physical structuring?; (3) how should the data be ordered so that they make sense and do allow its transformation in information - the logical structuring?; and, finally, (4) which information should be transmitted for which users when it is appropriate - final content and exit or output of the system?

Now, in the stage we are in, it is possible to configure an information system with certain rigor. However, some difficulties still perdure, therefore the answers are not just in the developed physical technologies: (1) which facts, events and occurrences in the development of the businesses should be apprehended as data that will be transformed in important information?; (2) how will we process such transformation, that implicates in certain readings, analyses and personal interpretations?; and (3) which information should users access, enabling an effective and efficient decision-making process?

In terms of the organization's operations, some light at the end of the tunnel is possible to notice - for instance, in Wight (1994) and Rowntree (1992); however, in strategic terms (Radford, 1978), a lot of ground will still have to be traveled, in spite of some practical progresses like SAP Strategic Enterprise Management ${ }^{3}$.

Then, how to examine the organizational situation? We face several indications of which data should be considered, how to obtain them and to order them in the exam of the organization (Albrecht, 1994; Schmitt, 1996). Even admitting this, 
the issue that still matters is how to structure them, for the diagnosis to be developed, electronically. The available methods, more or less effective in manual terms, show certain imprecision or do not present a configuration that allow us, strictly, to use them for an electronic diagnosis ${ }^{4}$.

Let us consider, methodically, a direction that is based in the renewed managerial thought (Drucker, 1989). Let us take the organization as a form of human association for certain attempted work, productive and collective, trying to serve individual and collective interests -convergent and divergent interests. This defines a network of organizational relationships in several levels.

Considering that Administration, in managerial terms, is the institutional element of conduction in the development of such relationships, reason for our usage of the concept of intervention, we could simplify the ambience of the administrator's interest, as: (1) Organizational survival, represented by the success or not of the organization $^{5}$; and (2) Organizational conditions in which such survival, as a larger variable, happens. These, we would understand as (1) Conditions of General Performance, representing the variable of instrumental success and the focus of the problem that matters for those who manage; and (2) Causal Conditions or conditions in which such performance happens, that can be seen through the categories (1) Environmental or external Conditions to the organization; (2) Internal Conditions and (3) Administrative Conditions. Finally, these last ones -administrative conditions - configuring several administrative models admitted as the causal conditions that would contain the final causes of the organizational problem causing element in the problem ${ }^{6}$.

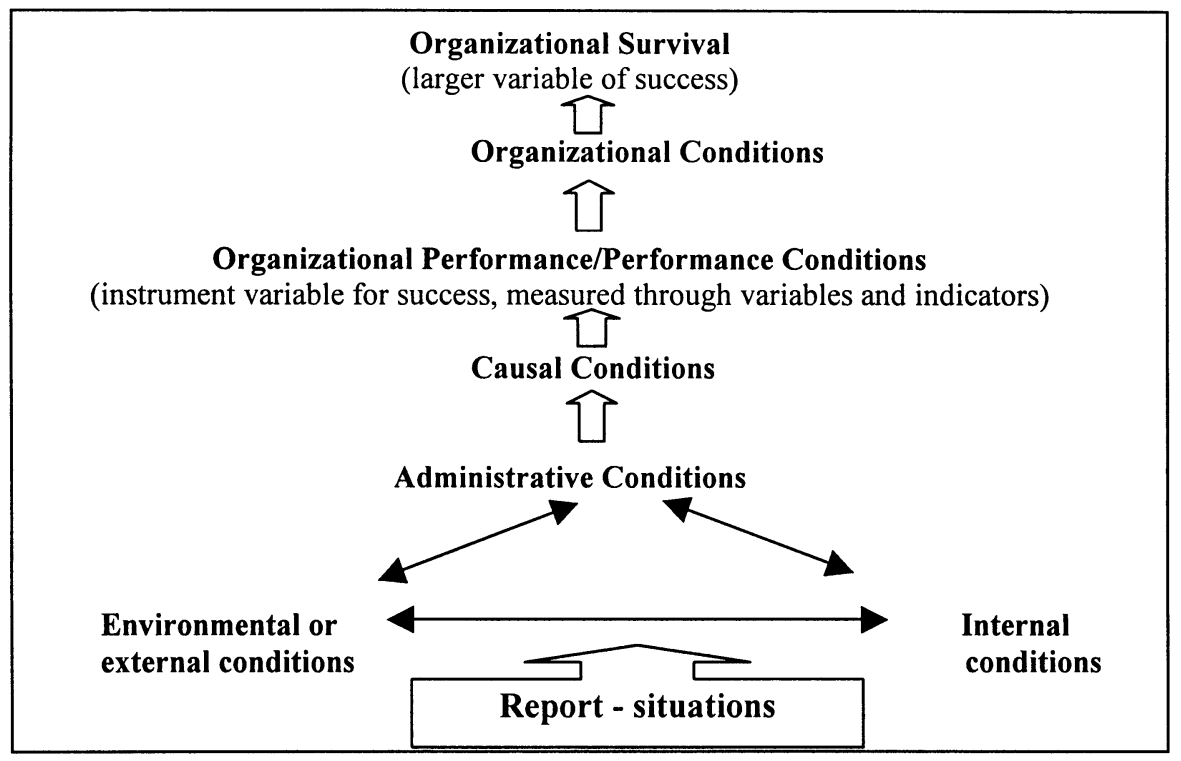

Figure 1 - A scheme of the Organizational Reality that matters to the Administrator

Thus, the diagnosis would include the following nucleus of procedures and of expected results: (1) exam of the significant deviations of performance (supposedly, consequences of administrative conditions in face of external and internal 
conditions) that are happening in the company, based on past and present data, in a pre-fixed time interval; (2) exam of the contextual conditions (external and internal conditions) that foster the referred deviation; and (3) exam of the possible, probable and more probable administrative causal conditions of the referred identified deviations, based on past and present conditions.

\section{FINAL CONSIDERATIONS: E-DIAGNOSIS VERSUS ORGANIZATIONAL KNOWLEDGE}

We now conclude highlighting a number of issues that deal with E-diagnosis's importance, scope, actualization, and relationship to organizational knowledge.

\subsection{What is E-diagnosis, its Importance and its General Scope}

We defined the electronic organizational diagnosis as the group of computational means, allowed by the current stage and in the development of IT that provides data and information regarding the organizational situation that matters to the decisionmaker, in almost real time ${ }^{7}$. It has to be pointed out, however, that emphasis only in IT, will not assure the appropriateness of this decision system.

It accelerates relevant "knowledge" for the decision-maker and it can be developed either in the general ambit of the organization or in its specific parts, as well as in functional areas or of projects. In other words, it allows an apprehension in appropriate time of the organizational problem that is of interest to the administrator.

Undoubtedly, this direction will depend on some requirements such as (1) scope or comprehensiveness of the situation that one wants to examine; (2) effective possibility of measuring the variables in study and readiness of data and information regarding the situation; and (3) structuring in network. This allow us to deduce for the existence of attempts of methods for a wide or restricted scope, for quantitative or qualitative variables, for factual and non-factual data and information, for delimitation of knowledge knots.

\subsection{How to accomplish it in the Organization.}

In spite of our satisfaction with the definition of the data and of the possible physical structuring now, the difficulty of the logical structuring perdures, as well as what we will do to build such decision system. In this case, the idea of successive attempts or of conformation of a system in an incremental mode (Inmon, 1997)), for the stage that we are in, it seems more appropriate than to try an integral system. Besides the possible critics of the "reengineers", we tend to believe that the most reasonable is the baby's step, the continuous improvement, or a mode that introduces the "new system", gradually. Inmon's comment (1997:269) for the case of systems of data, illustrates the issue: "in reality, it constitutes an excellent news the fact of the migration for the projected environment of data warehouse to be an activity led step by step and achieved by a finite portion per time."

Thus, we bring for discussion a direction among the possible ones. This would involve three moments of implementation: (1) some final users would be chosen, being constituted as strategic terminals; (2) the strategic terminals would be 
enlarged, incorporating functional areas or projects; and (3) it would extend for a network in that the knots represented key decision-makers directly linked to the performances that were associated to the problem of assuring the long term survival of the organization.

Likewise, in infra-structural terms, admitting the outline previously proposed for reading, analysis and interpretation of the organizational reality - the model of reception of data regarding the situation: exams of performances, of environment, of organizational resources and of administrative modes, the warehouse concept (Inmon, 1997) seems to us the most appropriate to make effective E-Diagnosis, because it implicates in a informational or analytic process, and not, operational. The informational or analytic process is the one that "assists to the managers' needs during the decision-makings process" (Inmon, 1997:x).

\subsection{From the Administrative Network to the Scheme of Creation of the Knowledge that matters.}

The obtaining of data and information and the construction of the convenient knowledge to the administrator, in almost real time, is a reality that is emerging or is demanded in the new business environment. In this aspect, the organizational virtualization is not just a tendency, but is also extremely favorable to accomplish the task of trying to build an appropriate knowledge inside the organization, for the administrator.

Thus, new instruments are needed that contemplate the network concept - EDiagnosis being one of them - already present in discussions amid business environments - for instance, Poirier \& Reiter (1997) and Lipnack \& Stamps (1994). The idea that the organization, in certain aspects, will present knowledge knots, constitutes a trail for a network of organizational knowledge management. Thus, e-diagnosis would represent an instrument of creation of organizational knowledge fostering more effective and efficient decisions, relatively.

Considering (1) the previously discussed structure for the development of an information system that supports the administrative decision, (2) the proposed diagnosis method and (3) the organizational variability, we would have:

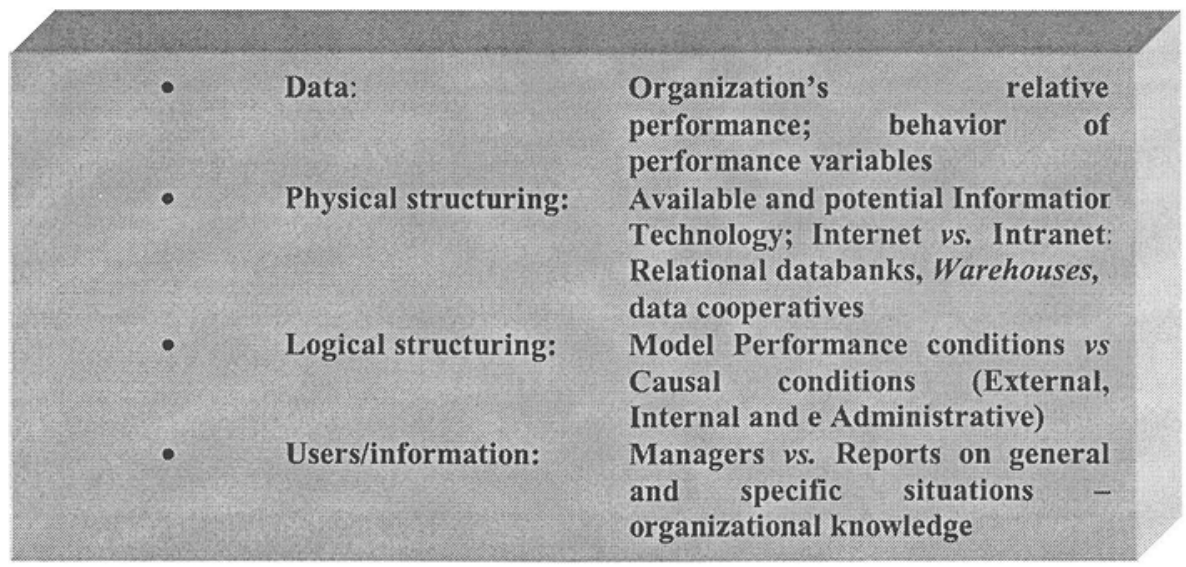


\begin{tabular}{l} 
The manager would be for us one dominant personalistic manifestation of who is involved with \\
administration. Other manifestations would be the Leader and the Politician. This assertion is based in our \\
recent studies about the administrative phenomenon, which for us, can be viewed under three \\
perspectives: managerial; leadership and politics. Any administrative act, i.e., act of an administrator \\
brings characters of these three forms, with a dominant one, depending on, obviously, the individual \\
exerting the act. Thus, this is how we can state that manger is that individual who, predominantly, \\
administers according to the prevalence of technical precepts, or rational-legal ones in the Weberian view. \\
${ }^{2}$ Time and space are defined in view of general and specific cultural patterns related to a person, group, \\
community or a larger society, giving certain traits to a reality both general and organizational \\
${ }^{3}$ See www.sap.com/solutions/br/sem/sem_over.htm \\
${ }^{4}$ Notwithstanding this evaluation, we understand that after some methodological adjustments, the \\
proposed schemes by those authors, may be useful for treating electronically the exam of the \\
organization. The challenge is, then, to achieve this adjustments giving data and information capturing, \\
processing, storing and destination the rigor that is demanded for electronic computation \\
5 Success is taken here as good (or bad) achievement or level in which survival is happening, indicating \\
its capacity to exist besides other things. It is worth noting that the concept of survival acquires, \\
conjointly, rational, super, and metarational natures \\
${ }^{6}$ It is our understanding that, in the managerial logic, administrative decisions, originating from accurate \\
(or not) analysis, conform what is and will be the business organization. In other words, given external \\
conditions, management makes viable required internal conditions and/or tries to alter external conditions \\
which affect organizational performance. \\
7 We understand that real time, in itself, is not possible ,constituting only an element of theoretical \\
discourse. Thus, what the authors call real time is what we call almost real time. \\
\hline
\end{tabular}

\section{REFERENCES}

1. ALBRECHT, K. Programando o futuro: o trem da linha norte. São Paulo: Makron Books, 1994

2. CADOZ, C. Realidade virtual. São Paulo: Ática, 1997

3. CHAMPY, J; NOHRIA, N (orgs) Avanço rápido: as melhores idéias sobre o gerenciamento de mudanças nos negócios. Rio de Janeiro: Campus, 1997

4. CHAUÍ, M. O conhecimento. In: Convite à filosofia, unidade 4, pp. 109-178. São Paulo: Ática, 1999

5. DAVENPORT, TH.; PRUSAK, L. Conhecimento empresarial: como as organizações gerenciam o seu capital intelectual. Rio de Janeiro: Campus, 1998

6. DAVIDOW, WH.; MALONE, MS. A corporação virtual: estruturação e revitalização da corporação para o século 21. São Paulo: Pioneira, 1993

7. DRUCKER, PF. As fronteiras da administração. São Paulo: Pioneira, 1989

8. GRAVE, PS.; SEIXAS, RA. Introdução ao E-Diagnosis como instrumento decisório administrativo: a possibilidade do diagnóstico ou da informação organizacional em tempo quase real. Anais do spolm/99, Rio de Janeiro, dezembro/1999

9. HESSEN, J. Teoria do conhecimento. Coimbra: Armênio Amado, 1980

10. INMON, WH. Como construir o data warehouse. Rio de Janeiro: Campus, 1997

11. KEPNER, CH.; TREGOE, BB. O administrador racional: uma abordagem sistemática à solução de problemas e tomada de decisões. São Paulo: Atlas, 1980

12. LIPNACK, J; STAMPS, J. The age of the network: organizing principles for the 21 st century. New York: John Wiley \& Sons, 1994

13. McGEE, J; PRUSAK, L. Gerenciamento estratégico da informação. Rio de Janeiro: Campus, 1994

14. POIRIER, CC.; REITER, SE. Otimizando sua rede de negócios. São Paulo: Futura, 1997

15. RADFORD, K. J. Information systems for strategic decisions. Reston, Virg.: Reston Pub, 1978

16. ROWTREE, D. Avaliação gerencial: um prático checklist para o aperfeiçoamento do gerente. São Paulo: Maltese-Norma, 1992

17. RUMMLER, GA.; BRACHE, AP. Melhores desempenhos das empresas: ferramentas para a melhoria da qualidade e da competitividade. São Paulo: Makron Books, 1992

18. SCHMITT, GR. Turnaround: a reestruturação dos negócios. São Paulo: Makron Books, 1996

19. SENGE, P; KLEINER, A; ROBERTS, C; ROSS, R; ROTH, G; SMITH, B. A dança das mudanças. Rio de Janeiro: Campus, 1999

20. WIGHT, O. Guia para a excelência operacional: checklist para melhorar o desempenho das empresas. Rio de Janeiro: Campus, 1994 